\title{
Analysis of supramolecular interactions in alendroniate alkali metal salts: synthesis, structure, and properties of novel sodium alendronate polymorph
}

\author{
Waldemar Maniukiewicz $^{1}$ (D) Joanna Bojarska ${ }^{1} \cdot$ Lesław Sieroń $^{1}$
}

Received: 12 April 2018 / Accepted: 29 May 2018 / Published online: 14 June 2018

(C) The Author(s) 2018

\begin{abstract}
A new polymorph of anhydrous sodium alendronate, $\mathrm{C}_{4} \mathrm{H}_{12} \mathrm{NO}_{7} \mathrm{P}_{2} \mathrm{Na}$, has been synthesized and characterized by single crystal $\mathrm{X}$-ray diffraction as well as infrared spectroscopy and thermal analysis. The title compound crystallizes in the monoclinic $P 2_{1} / \mathrm{c}$ space group. Asymmetric unit consists of one alendronic anion and one sodium cation. An interplay of classical strong $\mathrm{O}-\mathrm{H}^{\cdots}{ }^{\cdots} \mathrm{O}$, $\mathrm{N}-\mathrm{H}^{\cdots} \mathrm{O}$ and non-classical weak $\mathrm{C}-\mathrm{H}^{\cdots} \mathrm{O}$ hydrogen bonds creates 3D framework in the crystal. Contrary to previously reported sodium alendronate salts, in which $\mathrm{Na}^{+}$cation is surrounded by six-coordinated sphere, in compound (1), the $\mathrm{Na}^{+}$cation is fivecoordinated in a distorted trigonal-bipyramidal geometry. In order to provide a detailed investigation of the molecular arrangement in view of intermolecular interactions, the title compound was compared with alendronic acid and other known alkali metal alendronate salts, retrieved from the Cambridge Crystal Structure Database. The intercontacts were qualitatively and quantitatively compared using Hirshfeld surface analysis. It highlights that strong $\mathrm{O} \cdots \mathrm{H} / \mathrm{H}^{\cdots} \mathrm{O}$ and subtle $\mathrm{H}^{\cdots} \mathrm{H}$ contacts play an influential role in the total surface area. The $\mathrm{Me}^{+\cdots} \mathrm{H} / \mathrm{H}^{\cdots} \mathrm{Me}^{+}$and $\mathrm{Me}^{+\cdots} \mathrm{O} / \mathrm{O} \cdots \mathrm{Me}^{+}$contacts are meaningful as well. These evidently simple systems show a diverse complexity. Moreover, the powder X-ray diffraction, DSC, thermogravimetry/derivative thermogravimetry, and FT-IR results are also reported.
\end{abstract}

Keywords Bisphosphonates · Alendronic acid · Polymorphism $\cdot$ Crystal engineering $\cdot$ Hirshfeld surface analysis

\section{Introduction}

Human bone system-related diseases may remarkably deteriorate the quality of life. Very popular remedies in the treatment of these diseases are pharmaceuticals from bisphosphonates family, which can act as selective inhibitors of osteoclastic bone resorption. Currently, they are used in the clinical treatment of a variety of bone disorders such as osteoporosis, Paget's disease, and hypocalcemia [1], and are of some increasing importance in bone cancer therapy [2-4]. Last, works on metal coordination alendronate compounds have led to

Electronic supplementary material The online version of this article (https://doi.org/10.1007/s11224-018-1140-2) contains supplementary material, which is available to authorized users.

Waldemar Maniukiewicz

waldemar.maniukiewicz@p.lodz.pl

1 Institute of General and Ecological Chemistry, Lodz University of Technology, Żeromskiego 116, 90-924 Łódź, Poland new insight into their use in medicinal applications $[5,6]$, since metal complexation of a bioactive ligand may result in an improvement of the ligand's pharmacological properties. Also, these compounds show interesting magnetic, photochromic, and electrocatalytic properties [7-9]. Alendronic acid (see Scheme 1), chemically known as 4-amino-1hydroxybutylidene-1,1-bisphosphonic acid, is a member of a second-generation bisphosphonate class of active pharmaceutical ingredients, in which the P-C-P bridge replaces the P-O-P group of naturally occurring pyrophosphate. This feature allows the bisphosphonates to interact quite freely with the mineral phase of bone tissue $[10,11]$.

The alendronic acid offers also various opportunities for crystal engineering due to a number of accessible protonation points and a carbon chain with a terminal amino group, that allows the creation of strong $\mathrm{P}-\mathrm{O} \cdots \mathrm{H}$ and $\mathrm{N}-\mathrm{H}^{\cdots} \mathrm{O}$ hydrogen bonds. In order to provide a detailed systematical analysis of the molecular arrangement for this class of compounds, a new crystalline polymorphic form of anhydrous sodium alendronate (1) synthesized in our laboratory was compared with other known alendronate alkali metal salts. In-depth 


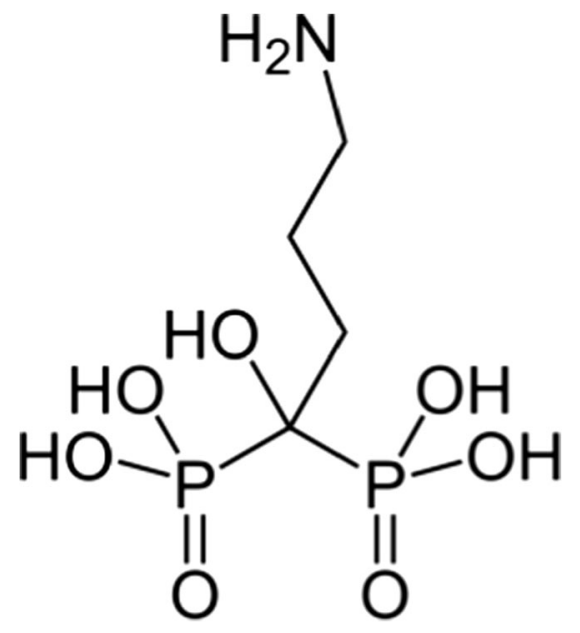

Scheme 1 Chemical structure of alendronic acid

search of literature and the Cambridge Crystal Structure Database (CSD Version 5.38, May 2017 release) [12] revealed the following salts with alkali cations such as the following: sodium, represented by CSD reference codes-UTOKAQ [13], PUQHAM, TEHWOS01 [14], TEHWOS [15]; lithium-EJEZUP [16]; potassium-PUQFOY, PUQFUE, PUQHEQ [14]; rubidium-PUQGAL, PUQGAL01, PUQGOZ, PUQHIU, PUQHOA [14]; and cesiumPUQGIT, PUQGUF, PUQHUG, PUQJAO [14]. Besides, alendronic acid crystal structures signed by CSD reference codes GOWZEX [17] and KOJGUL [18] were included into the analysis. So far, there were reports that the title compound exists in dehydrated [14, 15] and trihydrate [14] forms. Interestingly, in a new polymorph, the $\mathrm{Na}^{+}$is fivecoordinated in contrast to the other sodium salts, in which the cation is surrounded by six-coordinated sphere. Noteworthy, there is a high variability of coordination spheres in all analyzed crystals. Furthermore, the HS study [19-23] was employed to gain insight into intermolecular interactions responsible for crystal packing. Additional features for new anhydrous sodium alendronate polymorph were revealed by powder X-ray diffraction (PXRD), differential scanning calorimetry (DSC), thermogravimetry/derivative thermogravimetry (TG/DTG), and Fourier transform infrared spectroscopy (FT-IR).

\section{Experimental}

\section{Synthesis}

All chemicals were commercially purchased from Sigma Aldrich and used without further purification. Sodium carbonate, $\mathrm{Na}_{2} \mathrm{CO}_{3}(1.06 \mathrm{~g}, 10 \mathrm{mmol})$, and alendronic acid (2.49 g, $10 \mathrm{mmol})$ were added to water $(100 \mathrm{~mL})$, and after the evolution of $\mathrm{CO}_{2}$ ceased, the reaction mixture was heated and stirred for ca $3 \mathrm{~h}$. The white crystalline precipitate was washed with hot water and dried at room temperature (yield $1.96 \mathrm{~g}$, $79 \%$ ), m.p. $257-260^{\circ} \mathrm{C}$. Anal. Calcd for $\mathrm{C}_{4} \mathrm{H}_{12} \mathrm{NO}_{7} \mathrm{P}_{2} \mathrm{Na}(\%)$ : C 19.27, H 4.82, N 5.62. Found (\%): C 19.43, H 4.76, N 5.52.

\section{X-ray data collection and refinement}

Colorless prismatic crystals (see Fig. S1 in Supporting Information) were grown from water solution by slow evaporation at room temperature. Crystallographic data of (1) were recorded on the Bruker SMART APEXII CCD diffractometer with MonoCap capillary at $100 \mathrm{~K}$ using $\mathrm{Cu}-\mathrm{K} \alpha$ radiation. Data collection, cell refinement, data reduction, and absorption correction were carried out with the SMART and SAINTPLUS [24]. The structure was solved by direct methods using SHELXS97 [25] and all of the non-hydrogen atoms were refined anisotropically by full-matrix leastsquares technique on $F^{2}$ using SHELXL-97 [25]. All hydrogen atoms were located using difference Fourier techniques and refined with isotropic temperature factors. Molecular graphics were prepared by using Mercury program [26]. Additional details of the data collection and refinement are listed in Table 1. Selected bond lengths and dihedral angles are shown in Table S1 in Supplementary Materials.

Table 1 Crystallographic data of the title compound (1)

\begin{tabular}{ll}
\hline Empirical formula & $\mathrm{C}_{4} \mathrm{H}_{12} \mathrm{NO}_{7} \mathrm{P}_{2} \mathrm{Na}$ \\
\hline Formula weight $[\mathrm{g} / \mathrm{mol}]$ & 271.08 \\
Temperature $[\mathrm{K}]$ & $105(2)$ \\
Wavelength $[\AA]$ & 1.54178 \\
Crystal system & Monoclinic \\
Space group & $P 2_{1} / \mathrm{c}$ \\
Unit cell dimensions $\left[\AA{ }^{\circ}{ }^{\mathrm{o}}\right]$ & $a=6.8200(3)$, \\
& $b=10.1557(5)$, \\
& $c=14.6577(7)$, \\
Volume $\left[\AA^{3}\right]$ & $\beta=98.448(1)$ \\
$Z$ & $1004.20(8)$ \\
Density (calculated) $\left[\mathrm{mg} / \mathrm{m}^{3}\right]$ & 4 \\
Absorption coefficient $\left[\mathrm{mm}^{-1}\right]$ & 1.793 \\
$F(000)$ & 4.608 \\
Theta range for data collection $\left[{ }^{\mathrm{o}}\right]$ & 560 \\
Independent reflections & $5.318-66.997$ \\
Data/restraints/parameters & 1790 \\
Goodness-of-fit on $F^{2}$ & $1794 / 0 / 140$ \\
Final R indices (all data) & 1.133 \\
Largest hole and peak $\left(\mathrm{e} \AA^{-3}\right)$ & $\mathrm{R} 1=0.0471, \mathrm{wR} 2=0.1203$ \\
$R_{1}=\Sigma\|\mathrm{Fo}|-| \mathrm{Fc}\| / \Sigma\left|\mathrm{Fo}^{2}\right|, \mathrm{wR}_{2}=\left[\Sigma \mathrm{w}\left(\mathrm{F}_{\mathrm{o}}{ }^{2}-\mathrm{F}_{\mathrm{c}}{ }^{2}\right)^{2} / \Sigma \mathrm{w}\left(\mathrm{F}_{\mathrm{o}}{ }^{2}\right)^{2}\right]^{1 / 2}$, \\
Weighting scheme: $w=1 /\left[\sigma^{2}\left(\mathrm{~F}_{\mathrm{o}}{ }^{2}\right)+(\mathrm{xP})^{2}+\mathrm{yP}\right] ; x=0.0410 ; y=0.2322$ \\
\hline
\end{tabular}




\section{Hirshfeld surface analysis}

The molecular Hirshfeld surfaces partition the crystal space into non-overlapping molecular volumes and give unique information about each molecule within a crystal. The size and shape of Hirshfeld surface characterize the interactions between atoms in a crystal, and hence reflect different intermolecular interactions [19-23]. The normalized contact distance, $d_{\text {norm }}$, is a ratio including the distances of any surface point to the nearest nucleus internal to the surface, $d_{i}$, and the nearest nucleus external to the surface, $d_{e}$, and the van der Waals radii of the atoms, $r^{v d W}$, presented by equation.

$d_{\text {norm }}=\frac{d_{i}-r_{i}^{v d w}}{r_{i}^{v d w}}+\frac{d_{e}-r_{e}^{v d w}}{r_{e}^{v d w}}$

The $d_{\text {norm }}$ can be negative or positive sum of $d_{i}$ and $d_{e}$, when intercontacts are shorter or longer than the sum of the $\mathrm{vdW}$ radii of atoms, respectively. The three-dimensional HS surfaces, visualizing existing intercontacts on the electron density maps and corresponding two-dimensional FingerPrint (FP) plots, representing quantitative summary in the percentage of each contact type, were prepared by Crystal Explorer, ver. 3.1 [20]. Before the calculations, the bond lengths to $\mathrm{H}$ atoms were set to standardized neutron values $(\mathrm{O}-\mathrm{H}=0.983 \AA, \mathrm{C}-\mathrm{H}=1.083 \AA)$.

\section{X-ray powder diffraction}

The X-ray powder diffraction data were collected on a PANalytical X'Pert Pro MPD diffractometer by using $\mathrm{CuK} \alpha$ $(\lambda=1.54178 \AA$ ) radiation. The diffraction patterns were obtained at room temperature with step size of $0.0167^{\circ}$ and counting time $20 \mathrm{~s} / \mathrm{step}$ over angular range $3^{\circ}-60^{\circ}(2 \theta)$ using Bragg-Brentano geometry and a rotating flat-plate sample holder. The comparisons of diffraction patterns of new polymorph (1) and reported earlier anhydrous sodium alendronate [14] are shown in Fig. S2.

\section{Fourier transform infrared spectroscopy}

The FT-IR spectrum was recorded by using a Thermo-Nicolet 6700 FT-IR spectrometer (Thermo Scientific, USA) with MCT detector (photoconductive detector $\mathrm{HgCdTe}$ ) with a standard sample holder. Transmittance measurement was performed using $\mathrm{KBr}$ technique. Pellet was prepared with $5 \mathrm{wt} . \%$ of sodium alendronate and $95 \mathrm{wt} . \%$ of KBr. FT-IR spectrum of (1) was obtained at room temperature in the range of 4000 $650 \mathrm{~cm}^{-1}$. The IR spectrum of the complex (1) displays a weak broad absorption centered at approximately 3200 $3000 \mathrm{~cm}^{-1}$ attributable to - $\mathrm{OH}$ and NH- stretching vibrations (see Supporting Information Fig. S3). A complex series of absorption bands between 1250 and $1000 \mathrm{~cm}^{-1}$ is also observed in the spectrum, and these are in the typical region for $\mathrm{P}-\mathrm{O}$ stretching vibrations [27]. The interpretation of these $\mathrm{P}-\mathrm{O}$ stretching vibrations is complicated by the differing coordination modes of each phosphonate group.

\section{Thermal analysis}

The thermal properties of sodium aledronate were studied by DSC and TG/DTG techniques in air in the range of temperature from 16 up to $304{ }^{\circ} \mathrm{C}$ and at a heating rate of $10{ }^{\circ} \mathrm{C} \mathrm{min}{ }^{-1}$, by using Netzsch TG 209 apparatus in flow of dynamic air atmosphere $v=20 \mathrm{~mL} \mathrm{~min}^{-1}$ in ceramic crucibles. The DSC curves of anhydrous sodium alendronate (1) are illustrated in Fig. S4. The TG and DTG results indicated that compound is stable up to $259^{\circ} \mathrm{C}$.

\section{Results and discussion}

\section{The crystal structure and comparison with other alendronate salts}

The crystal structure of (1) was determined by single crystal $\mathrm{X}$-ray diffraction study. The compound crystallizes in the space group $P 2_{1} / \mathrm{c}$ (No. 14), belonging to the monoclinic system, with one alendronic anion and one sodium cation per asymmetric unit. A view of the molecular structure with atom numbering scheme is depicted in Fig. 1.

Likewise to previously reported alendronate alkali metal salts, the structure of (1) has zwitterionic character with a positively charged ammonium group balanced by one of the negatively charged phosphonate oxygens. The geometry around the $\mathrm{P}$ atoms is tetrahedral and the $\mathrm{P}-\mathrm{O}$ bond lengths are close to 1.50 and $1.55 \AA$ for the $\mathrm{P}-\mathrm{O}$ (unprotonated) and $\mathrm{P}$ $\mathrm{O}$ (protonated) distances, respectively. The P-C bond distances 1.834(3) and 1.864(3) $\AA$ and P-C-P bond angle of

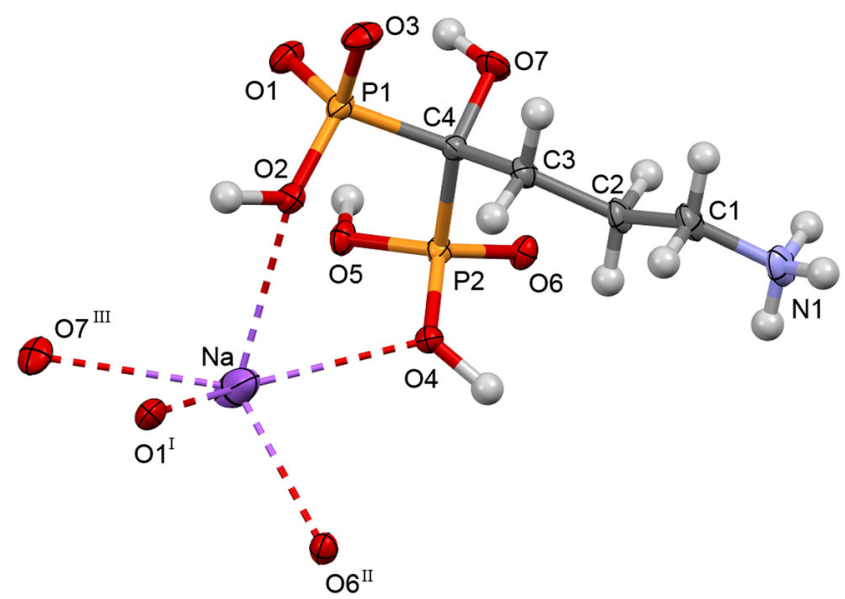

Fig. 1 ORTEP plot and atom numbering scheme of (1). The displacement ellipsoids are shown with $50 \%$ probability 
Table 2 Hydrogen bond geometry of the title compound

\begin{tabular}{llllll}
\hline $\mathrm{D}-\mathrm{H} \cdots \mathrm{A}$ & $\mathrm{D}-\mathrm{H}(\AA)$ & $\mathrm{H}^{\cdots} \mathrm{A}(\AA)$ & $\mathrm{D} \cdots \mathrm{A}(\AA)$ & $\mathrm{D}-\mathrm{H} \cdots \mathrm{A}\left({ }^{\circ}\right)$ & Symmetry code \\
\hline $\mathrm{N} 1-\mathrm{H} 1 \cdots \mathrm{O} 7$ & 0.91 & 2.44 & $3.329(4)$ & 166 & $1+\mathrm{x}, \mathrm{y}, \mathrm{z}$ \\
$\mathrm{N} 1-\mathrm{H} 2 \cdots \mathrm{O} 1$ & 0.91 & 2.52 & $3.088(4)$ & 121 & $1+\mathrm{x}, 3 / 2-\mathrm{y}, 1 / 2+\mathrm{z}$ \\
$\mathrm{N} 1-\mathrm{H} 2 \cdots \mathrm{O} 5$ & 0.91 & 1.97 & $2.824(4)$ & 155 & $1+\mathrm{x}, 3 / 2-\mathrm{y}, 1 / 2+\mathrm{z}$ \\
$\mathrm{O} 2-\mathrm{H} 2 \mathrm{O} \cdots \mathrm{O} 5 *$ & 1.16 & 1.31 & $2.469(3)$ & 176 & $-\mathrm{x},-1 / 2+\mathrm{y}, 1 / 2-\mathrm{z}$ \\
$\mathrm{N} 1-\mathrm{H} 3 \cdots \mathrm{O} 6$ & 0.91 & 1.95 & $2.833(4)$ & 164 & $1-\mathrm{x}, 2-\mathrm{y}, 1-\mathrm{z}$ \\
$\mathrm{O} 4-\mathrm{H} 40 \cdots \mathrm{O} 1$ & 1.07 & 1.43 & $2.496(3)$ & 175 & $1+\mathrm{x}, \mathrm{y}, \mathrm{z}$ \\
$\mathrm{O} 7-\mathrm{H} 70 \cdots \mathrm{N} 1$ & 0.84 & 2.50 & $3.329(4)$ & 170 & $-1+\mathrm{x}, \mathrm{y}, \mathrm{z}$ \\
$\mathrm{C} 1-\mathrm{H} 4 \cdots \mathrm{O} 4$ & 0.99 & 2.48 & $3.437(4)$ & 162 & $\mathrm{x}, 3 / 2-\mathrm{y}, 1 / 2+\mathrm{z}$ \\
$\mathrm{C} 1-\mathrm{H} 5 \cdots \mathrm{O} 3$ & 0.99 & 2.56 & $3.176(4)$ & 121 & $1+\mathrm{x}, \mathrm{y}, \mathrm{z}$ \\
\hline
\end{tabular}

*Intramolecular hydrogen bond

$112.2(2)^{\circ}$ are in a good agreement with the corresponding values found in analogue compounds. It seems particularly interesting to analyze the change of coordination sphere around the central atom. As has already been reported, these systems demonstrate diverse complexity, which increases with the central cation radius. Lithium alendronate salts revealed four-coordinate tetrahedral $\mathrm{Li}^{+}$cation [16]; sodium salts, six-coordinate octahedral $\mathrm{Na}^{+}$[13-15]; potassium salts, seven-coordinated $\mathrm{K}^{+}[14]$; and rubidium, 6/7/8-coordinated $\mathrm{Rb}^{+}$[14]; while cesium, 7/8/9-coordinated $\mathrm{Cs}^{+}$[14] . Surprisingly, $\mathrm{Na}^{+}$cation in (1) is surrounded by a fivecoordinated sphere through three of the hydroxyl $(-\mathrm{OH})$ and two oxygen atoms of the phosphonate $(\mathrm{P}=\mathrm{O})$ groups. The $\mathrm{Na}-$ O distances vary from 2665(3) to 2913(3) $\AA$ forming distorted
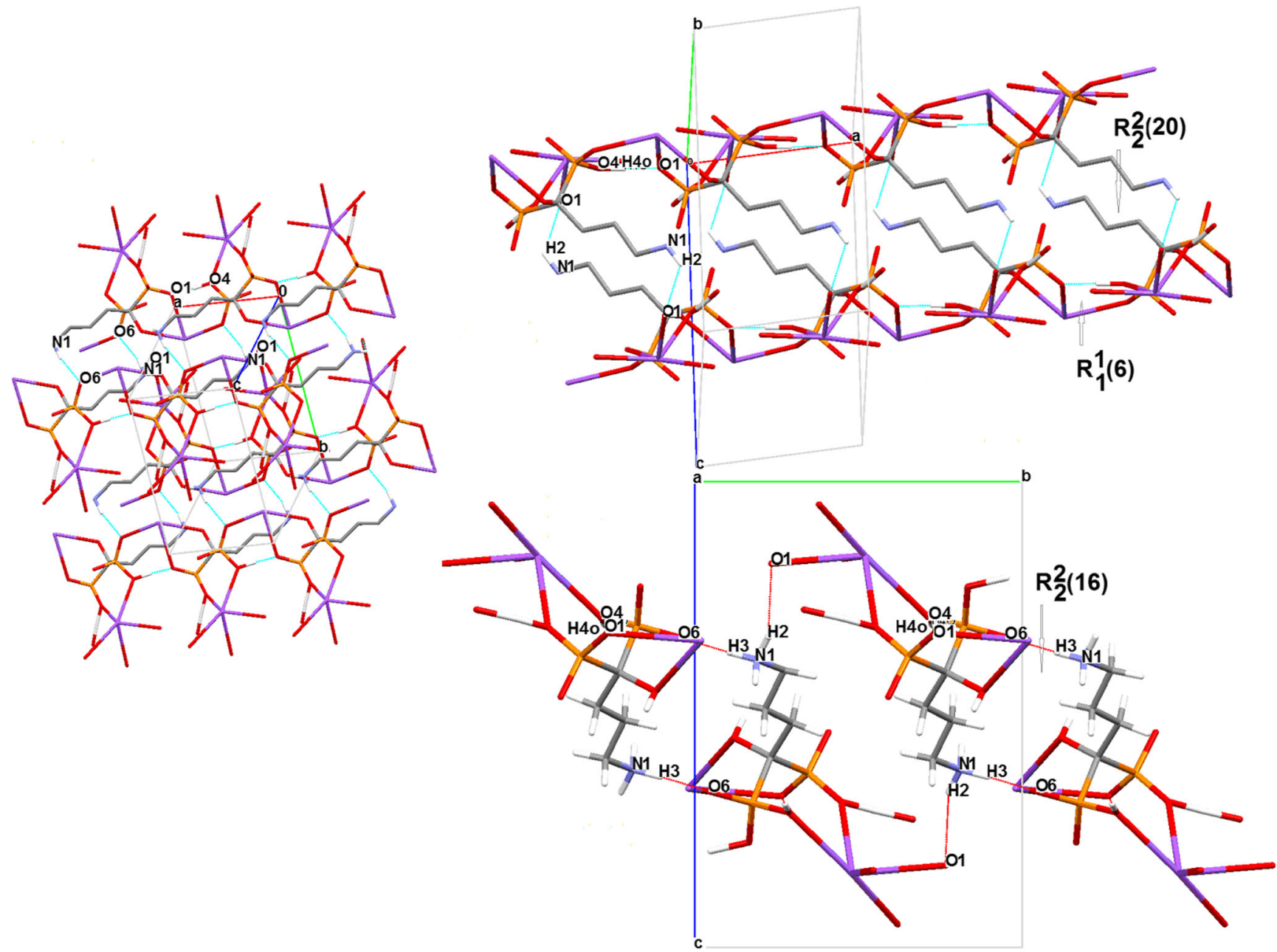

Fig. 2 A partial packing diagram for sodium alendronate (1). Intermolecular hydrogen bonds are indicated by dotted lines 
trigonal-bipyramidal geometry around $\mathrm{Na}^{+}$cation. These observed distances are longer than those described in the literature [15], in which the Na-O distances change between 2.228 and $2.580 \AA$. Another interesting feature found for (1) concerns Kitaigorodsky's Packing Index, so-called KPI index [28], estimated in Platon program [29]. It gives a percent of filled space of $82.2 \%$ and therefore there is no accessible space in the network for solvents. It is the largest value among all known sodium alendronate salts, presenting the most closepacked structure. Crystal data, including KPI factor (for sodium alendronate salts), of analyzed alendronate structures retrieved from the CSD are summarized in Table S2. Furthermore, the title structure has been carefully examined along with other related alendronates due to identified trends in 3D molecular arrangements and H-bond interaction patterns. The packing of the molecules in (1) is dominated by strong classical $\mathrm{O}-\mathrm{H}^{\cdots} \mathrm{O}, \mathrm{N}-\mathrm{H}^{\cdots} \mathrm{O}$ and weak non-classical C$\mathrm{H}^{\cdots} \mathrm{O}$ hydrogen bonds. Two $\mathrm{P}-\mathrm{OH}$, three $\mathrm{P}=\mathrm{O}$, and three hydrogen atoms of $\mathrm{NH}_{3}{ }^{+}$group are involved in intermolecular hydrogen bonding. Only one intramolecular H-bond exists utilizing the $\mathrm{P}-\mathrm{O}-\mathrm{H}^{\cdots} \mathrm{O}=\mathrm{P}$ groups. The cooperativity of all existing $\mathrm{H}$-bond interactions leads to creating the distinctive three-dimensional H-bonding array. The geometric parameters characterizing H-bonds are listed in Table 2.

The lengths of intermolecular $\mathrm{H}$-bonds range from $2.469(3)$ to 3.437(4) $\AA$, while the angles change from $121^{\circ}$ to $176^{\circ}$. The four stronger $(\mathrm{D} \cdots \mathrm{A}$ distances $<2.9 \AA$ ) and five weaker $(\mathrm{D} \cdots \mathrm{A}>2.9 \AA)$ hydrogen bonds of the type $\mathrm{O}-\mathrm{H}^{\cdots} \mathrm{O}$, $\mathrm{N}-\mathrm{H}^{\cdots} \mathrm{O}, \mathrm{O}-\mathrm{H}^{\cdots} \mathrm{N}$, and $\mathrm{C}-\mathrm{H}^{\cdots} \mathrm{O}$ are observed. The profound comparative investigation revealed enormous variety of $\mathrm{H}$ bond synthons. Alendronate anions are connected into dimers in a head-to-tail manner. According to Etter and Bernstein's graph set theory [30,31], the $R_{1}^{1}(6)$ rings in (1) created by O4$\mathrm{H} 40 \cdots \mathrm{O} 1$ bonds generate corrugated polymeric 1D chain of corner-sharing $\mathrm{NaO}_{5}$ polyhedra elongated along crystallographic $a$ axis. Additionally, $R_{2}^{2}(16)$ and $R_{2}^{2}(20)$ motifs formed through $\mathrm{N} 1-\mathrm{H} 3 \cdots \mathrm{O} 6$ and $\mathrm{N} 1-\mathrm{H} 2 \cdots \mathrm{O} 1$, respectively, linking polymeric chains into $2 \mathrm{D}$ sheet. The crystal packing drawing with intermolecular hydrogen bonds in the unit cell is showed in Fig. 2. The 3D molecular self-assemblies of alendronate salts are distinguishable. The structures revealed one-dimensional and two-dimensional pseudo-coordination
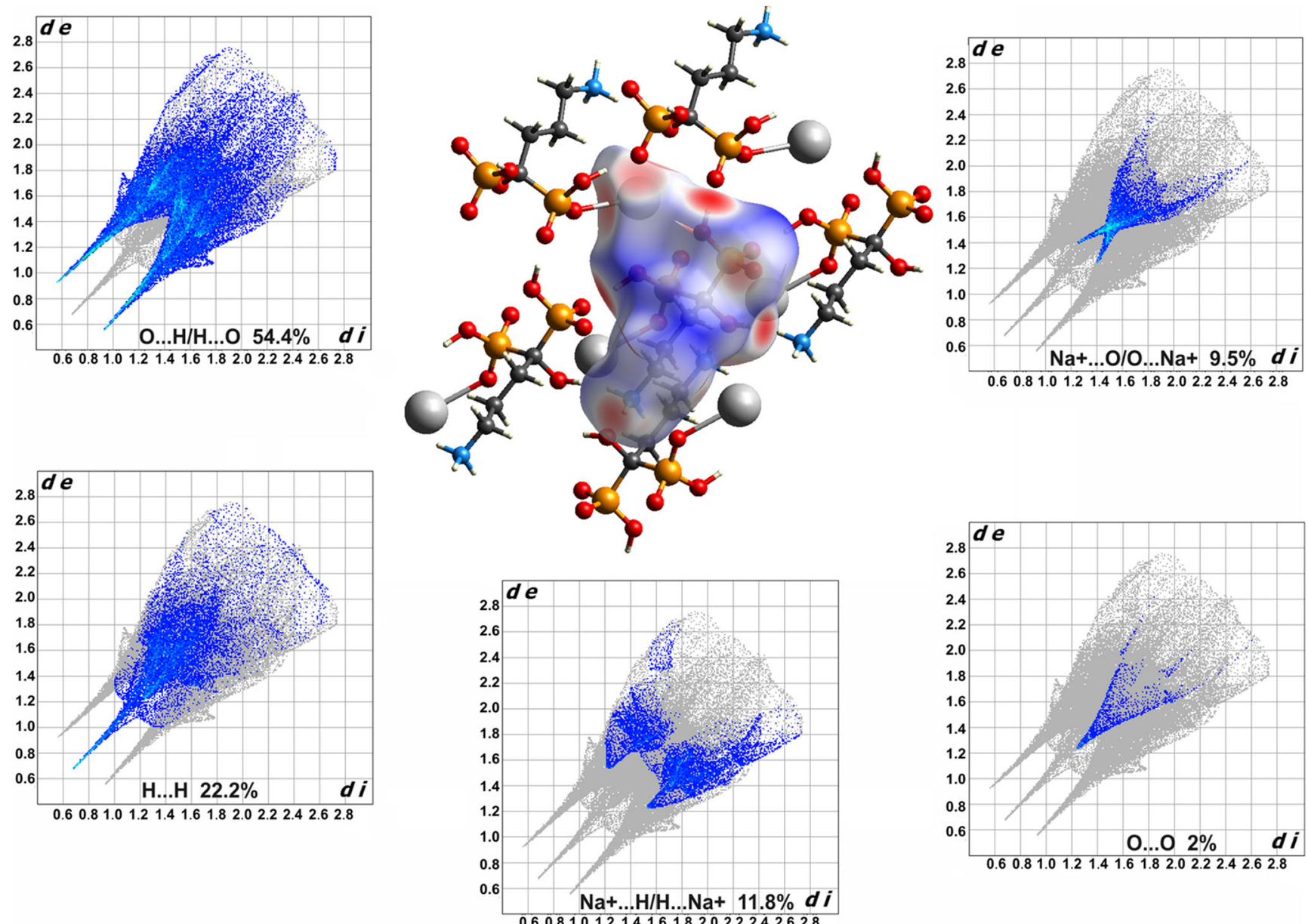

Fig. 3 Hirshfeld surfaces mapped with $d_{\text {norm }}$ (in the middle) and fingerprint plots resolved into $\mathrm{O} \cdots \mathrm{H} / \mathrm{H} \cdots \mathrm{O}, \mathrm{H}^{\cdots} \cdots \mathrm{H}, \mathrm{Na}^{+} \cdots \mathrm{H}^{\prime} \mathrm{H}^{\cdots} \mathrm{Na}^{+}, \mathrm{O} \cdots \mathrm{O}$, and $\mathrm{Na} a^{+} \cdots \mathrm{O} /$ $\mathrm{O} \cdots \mathrm{Na}^{+}$contacts, showing the percentages of contacts contributing to the total Hirshfeld surface area of molecule (1) 


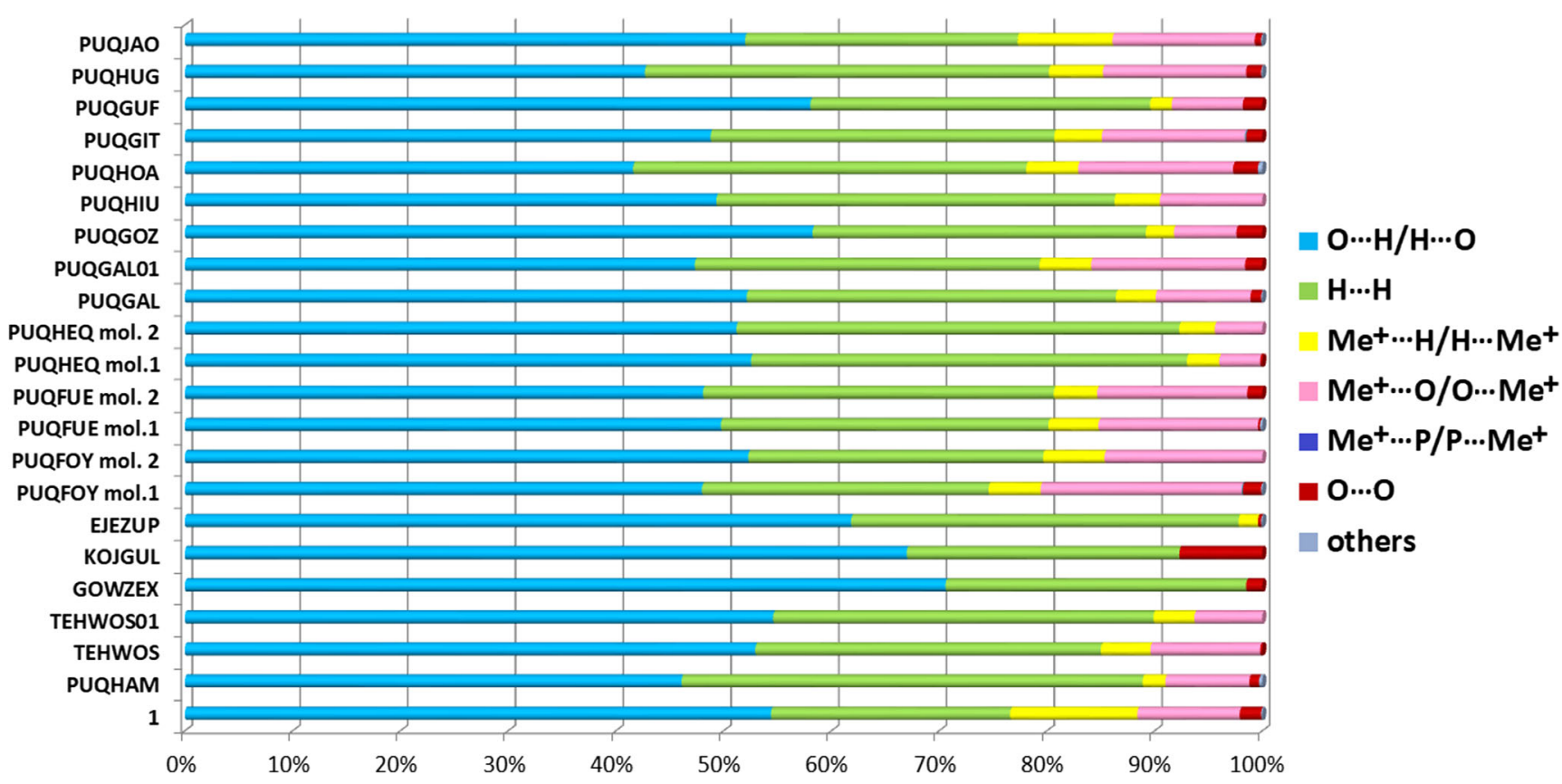

Fig. 4 Relative contributions of various intermolecular contacts to the Hirshfeld surfaces area in analyzed structures

polymeric architectures and in structure (1) has intermediate character between the anhydrous polymorph determined from the powder data [13] and hydrated sodium salts [14, 15]. The $R_{2}^{2}(20)$ synthon is observed in all sodium alendronate salts. Notably, among all sodium alendronates, only in the case of PUQHAM crystal [14], the intramolecular graph set synthons, described by $S^{1}{ }_{1}(6)$ and $S^{1}{ }_{1}(7)$ motifs, were found.

\section{Molecular Hirshfeld surface analysis}

Herein, Fig. 3 presents the HS together with resolved FP plots quantifying the percentage contributions of $\mathrm{O} \cdots \mathrm{H} / \mathrm{H}^{\cdots} \mathrm{O}$, $\mathrm{H}^{\cdots} \mathrm{H}, \mathrm{Na}^{+\cdots} \mathrm{H} / \mathrm{H}^{\cdots} \mathrm{Na}^{+}, \mathrm{O} \cdots \mathrm{O}, \mathrm{Na}^{+\cdots} \mathrm{O} / \mathrm{O}^{\cdots} \mathrm{Na}^{+}$contacts involved in crystal packing of (1). The information given in Table 2 is summarized effectively in the Hirshfeld surfaces as the circular red areas indicating strong $\mathrm{H}$-bonding interactions, such as $\mathrm{O}-\mathrm{H}^{\cdots}{ }^{\cdots} \mathrm{O}, \mathrm{N}-\mathrm{H}^{\cdots} \mathrm{O}$, and $\mathrm{O}-\mathrm{H}^{\cdots}{ }^{\cdots} \mathrm{N}$, white-colored areas correspond to regions with weak contacts $\mathrm{C}-\mathrm{H}^{\cdots} \mathrm{O}$, while the blue areas are considered to be free of significant intermolecular contacts. The HS diagram was generated using a high surface resolution. The electron density with the function $d$ norm was mapped by using a fixed color scale of 0.5 and -1.5 for red and blue, respectively. The FP plots were drawn on the $d_{e}$ and $d_{i}$ distances, from the HS to the nearest outside-external and inside-internal atoms, respectively. The $d_{e}-d_{i}$ pairs are in intervals of $0.01 \AA$.

From the 2D FP plot analysis, it was found that the $\mathrm{O} \cdots \mathrm{H} /$ $\mathrm{H}^{\cdots} \mathrm{O}$ bonds are dominant and cover the total HS area in the range from $41.6 \%$ in rubidium salt (PUQHOA) [14] to $70.6 \%$ in alendronic acid (GOWZEX) [17]. On the other hand, subtle interactions such as $\mathrm{H}^{\cdots} \mathrm{H}$ are also significant contributors, associating from $22.2 \%$ in (1) to $42.8 \%$ in sodium salt (PUQHAM) [14], providing extra stabilization in addition to the presence of the abovementioned strong hydrogen bonds. Besides, $\mathrm{Me}^{+\cdots} \mathrm{H} / \mathrm{H}^{\cdots} \mathrm{Me}^{+}$(where $\mathrm{M}^{+}$means alkali metal cations) contacts seem also important, although we observe here some differences among the analyzed structures (from $1.8 \%$ for EJEZUP to $11.8 \%$ in (1)). At the similar level are $\mathrm{Me}^{+\ldots} \mathrm{O} /$ $\mathrm{O}^{\cdots} \mathrm{Me}^{+}$contacts (from $3.8 \%$ in PUQHEM to $18.6 \%$ in PUQFOY). Notably, contributions of $\mathrm{O} \cdots \mathrm{O}$ and $\mathrm{Me}^{+\cdots} \mathrm{H} /$ $\mathrm{H}^{\cdots} \mathrm{Me}^{+}$are the greatest in (1) among sodium salts. Relative percentage contributions of individual interactions to the HS areas existing in all analyzed compounds are summarized in Fig. 4 and Table S3.

\section{Conclusions}

This article reports crystal structure of new anhydrous sodium alendronate (1) polymorph: a crystallographic study revealing the different geometry of this new form from those described in the literature previously. The comparison with other known alendronate alkali metal salts proved that these simple systems demonstrate considerable versatile structural complexity. While it was found that the intermolecular interactions and packing arrangements appear to be consistent among structures, this was verified by HS analysis which allowed the identification in a quantitative way of all interactions in the alendronate salt crystals. The $\mathrm{O}{ }^{\cdots} \mathrm{H} / \mathrm{H}^{\cdots} \mathrm{O}, \mathrm{H}^{\cdots} \mathrm{H}$, and $\mathrm{Me}^{+}$ ${ }^{\cdots} \mathrm{O}(\mathrm{H}) / \mathrm{O}(\mathrm{H}){ }^{\cdots} \mathrm{Me}^{+}$interactions play a major role in all analyzed self-assemblies. To sum up, discussed observations can 
be useful from the crystal engineering point of view of this second-generation class of bisphosphonate drugs.

\section{Compliance with ethical standards}

Conflict of interest The authors declare that they have no conflict of interest.

Open Access This article is distributed under the terms of the Creative Commons Attribution 4.0 International License (http:// creativecommons.org/licenses/by/4.0/), which permits unrestricted use, distribution, and reproduction in any medium, provided you give appropriate credit to the original author(s) and the source, provide a link to the Creative Commons license, and indicate if changes were made.

\section{References}

1. Prinsloo PJJ, Hosking DJ (2006). Ther. Clin. Risk Manag 2(3): 235-249

2. Burnei G, Vlad C, Georgescu I, Gavriliu TS, Dan D (2008). J Am Acad Othop Surg 6:356-366

3. Pornes AG, Holland SD, Gertz BJ (1999). Clin Pharmacokinet 36: 315-328

4. Oida T, Mimatsu K, Kano H, Kawasaki A, Kuboi Y, Fukino N, Kida K, Amano S (2012). Hepatogastroenterol 59:444- 447

5. Liu D, Kramer SA, Huxford-Phillips RC, Wangm S, Della Rocca J, Lin W (2012). Chem Commun 48:2668-2670

6. Alvarez E, Marquez AG, Devic T, Steunou N, Serre C, Bonhomme C, Gervais C, Izquierdo-Barba I, Vallet-Regi M, Laurencin D, Mauri F, Horcajada P (2013). CrystEngComm 15:9899-9905

7. Freire E, Quintero M, Vega D, Baggis R (2013). Inorg. Chim. Acta 394:229-236

8. Yang L, Zhou Z, Ma P, Wang J, Niu J (2013) J. Cryst Growth Des 13:2540-2547

9. El Moll H, Kemmerge-Mbouguen JC, Itaouas M, Taulelle F, Marrot J, Cadot E, Mialane P, Floquet S, Dolbecq A (2012). Dalton Trans 41:9955-9963

10. Compston JE (1994). Br Med J 309:711-715

11. Martin TJ, Grill V (2000). Aust Prescr 23:130-132
12. Allen FH (2002). Acta Cryst B58:380-388

13. Asnani M, Vyas K, Bhattacharaya A, Devarakonda S, Chakraborty S, Mukherjee AK (2009). J Pharm Sci 98(6):2113-2121

14. Deacon GB, Forsyth CM, Greenhill NB, Junk PC, Wang J (2015). Cryst. Growth Des. 15:4646-4662

15. Vega D, Baggio R, Garland MT (1996). Acta Cryst C52: 2198-2201

16. Deacon GB, Greenhill NB, Junk PC, Wiecko M (2011). J Coord Chem 64:179-185

17. Chanessian J, Avenel D, Manouni DE, Benramdane M (1997). Phosphorus, Sulfur, Silicon, Relat. Elem 129:99-110

18. Leroux Y, El Manouni D, Safsaf A, Neuman A, Gillier H (1991). Phosphorus, Sulfur, Silicon, Relat. Elem 63:181-191

19. Spackmann MA, McKinnon JJ (2002). Cryst Eng Comm 4: 378-392

20. S.K. Wolff, D.J. Grimwood, J.J. McKinnon, M.J. Turner, D. Jayatilaka, M.A. Spackman, (2012), CrystalExplorer (Version 3.1), University of Western Australia

21. McKinnon JJ, Spackmann MA, Mitchell AS (2004). Acta Cryst B60:627-668

22. Rohl AL, Morer M, Kaminsky W, Claborn K, McKinnon JJ, Kahr B (2008). Cryst.Growth Des 8:4517-4525

23. Parkin A, Barr G, Dong W, Gilmore CJ, Jayatilaka D, McKinnon JJ, Spackmann MA, Wilson CC (2007). CrystEngComm 9:648-652

24. Bruker, SHELXTL (Version 6.10), Saint-Plus (Version 6.02) and SMART-WNT2000 (Version 5.622), Bruker AXS Inc, Madison, Wisconsin, USA (2000)

25. Sheldrick GM (2008) SHELXS-97. Acta Cryst A64:112-122

26. Macrae CF, Bruno IJ, Chisholm JA, Edgington PR, McCabe P, Pidcock E, Rodriguez-Monge L, Taylor R, van de Streek J, Wood PA (2008). J Appl Crystallogr 41:466-470

27. Zenobi MC, Luengo CV, Avena MJ, Rueda E, Spectrochim H (2008). Acta, Part A70:270-276

28. Kitaigorodskii AI (1973) Molecular crystals and molecules. Academic Press, New York

29. Spek AL (2009). Acta Crystallogr., Sect D: Biol Crystallogr 65: 148-155

30. Bernstein J, Davis RE, Shimoni L, Chang NL (1995). Angew Chem Int Ed Engl 34:1555-1573

31. Etter MC, McDonald JC, Bernstein J (1990). Acta Cryst B46:256-262 